\title{
Case of Severe Accidental Hypothermia Cardiac Arrest in a Subtropical Climate and Review of Management
}

This article was published in the following Dove Press journal: Open Access Emergency Medicine

\author{
Terence Chau $\mathbb{D}^{1 *}$ \\ Merlyn Joseph $\mathbb{D}^{2, *}$ \\ Jesus Ledesma Jr ${ }^{3}$ \\ David Wei Hau Hsu (iD ${ }^{3}$ \\ 'Department of Pharmacy, Cooper \\ University Hospital, Camden, NJ, 08I03, \\ USA; ${ }^{2}$ Texas A\&M University, Irma Lerma \\ Rangel College of Pharmacy, Houston, \\ TX 77030, USA; ${ }^{3}$ Emergency \\ Department, Memorial Hermann \\ Memorial City Medical Center, Houston, \\ TX, 77024, USA
}

*These authors contributed equally to this work

\begin{abstract}
A patient was brought to the hospital with severe accidental hypothermia due to cold exposure associated with acute alcohol intoxication. Initial bladder core temperature was $21^{\circ} \mathrm{C}$ $\left(70^{\circ} \mathrm{F}\right)$. The patient was agitated and combative with altered mental status and suffered rescue collapse during transport. Initial rhythm was ventricular fibrillation and we initiated a standard advanced cardiac life support (ACLS) protocol with rewarming measures. The patient received $28 \mathrm{mg}$ of epinephrine and 13 shocks. Active and passive rewarming were initiated without extracorporeal rewarming. The patient achieved return of spontaneous circulation (ROSC) at a core temperature of $23.8^{\circ} \mathrm{C}\left(74.8^{\circ} \mathrm{F}\right)$. Patient was discharged 15 days later neurologically intact with no organ damage. The clinical management and implications for further research in severe accidental hypothermia management are discussed. In patients with severe accidental hypothermia (defined as $<30^{\circ} \mathrm{C}$ or $<86^{\circ} \mathrm{F}$ ) in cardiac arrest, the optimal rewarming technique, use of epinephrine, and time when defibrillation should be attempted remain controversial. In our patient, the patient achieved ROSC in less than 2 hours with standard ACLS procedures despite a minimal increase in core temperature $\left(21^{\circ} \mathrm{C}\right.$ to $23.8^{\circ} \mathrm{C}$ or $70^{\circ} \mathrm{F}$ to $\left.73.9^{\circ} \mathrm{F}\right)$.
\end{abstract}

Keywords: accidental severe hypothermia, cardiac arrest, ACLS

\section{Case Presentation}

\section{Patient Presentation}

A patient was found was found unresponsive on the ground in an outdoor environment. The overnight weather was clear with low temperature of $2.7^{\circ} \mathrm{C}\left(36.9^{\circ} \mathrm{F}\right)$ with $43 \%$ humidity. Emergency medical services (EMS) arrived at the scene at 8:43 AM and noted the patient's clothes were wet and his skin felt cold. The patient was responsive with eyes opening to touch. The patient was transported to the nearest emergency department and transferred care at 8:53 AM. Upon arrival at the emergency department's ambulance bay, the patient was agitated, combative, and had altered mental status. Attempts were made to move the patient out of the ambulance. During transfer, the patient became apneic and unresponsive. Chest compressions and bag-mask ventilation were initiated as the patient was transported into the emergency department. Defibrillator pads were place on the patient and the initial rhythm was ventricular fibrillation.

\section{CPR Course}

The patient's wet clothing was removed and cardiopulmonary resuscitation (CPR) was resumed at 8:58 AM with manual compressions and endotracheal intubation. A urinary
Correspondence: Terence Chau

Cooper University Hospital, One Cooper

Plaza, Camden, NJ 08103, USA

Tel +I 8563422975

Fax +I 8569688408

Email chau-terence@cooperhealth.edu
Open Access Emergency Medicine 2020:12 399-404

cc) (5) 2020 Chau et al. This work is published and licensed by Dove Medical Press limited. The full terms of this license are available at https://www.dovepress.com/terms.php you hereby accept the Terms. Non-come the Creative Commons Attribution - Non Commercial (unported, v3.0) License (http:///creativecommons.org/licenses/by-nc/3.0/). By accessing the work permission for commercial use of this work, please see paragraphs 4.2 and 5 of our Terms (https://www.dovepress.com/terms.php). 
catheter with temperature sensor was inserted and revealed a core temperature of $21^{\circ} \mathrm{C}\left(69.8^{\circ} \mathrm{F}\right)$, by definition severe hypothermia. Rewarming measures were implemented and involved: the infusion of $43^{\circ} \mathrm{C}$ IV saline via two Hotline ${ }^{\circledR}$ (Smiths Medical, Minneapolis, Minnesota, United States) fluid warmers through both central and peripheral IV routes; warm fluid bladder lavage; warm water lavage through the nasogastric tube; application of the Bair Hugger ${ }^{\mathrm{TM}}$ (3M, St. Paul, Minnesota, United States) warming blanket system at the $43^{\circ} \mathrm{C}$ temperature setting; and eventually Artic Sun ${ }^{\circledR}$ (Medivance Corp, Louisville, Colorado, United States) initiation to start normothermic therapy at $37^{\circ} \mathrm{C}$.

Initial point-of-care laboratory studies were significant for a low sodium of $114 \mathrm{mEq} / \mathrm{L}$, potassium of $4.3 \mathrm{mEq} / \mathrm{L}$, high chloride level of $111 \mathrm{mEq} / \mathrm{L}$, low HCO3- of $20 \mathrm{mEq} /$ $\mathrm{L}$, low ionized calcium of $0.95 \mathrm{mMol} / \mathrm{L}$, and $\mathrm{pH}$ of 7.07 . Whole blood laboratory studies obtained one hour later were significant for sodium of $138 \mathrm{mEq} / \mathrm{L}$, low potassium of $3.0 \mathrm{mEq} / \mathrm{L}$, low $\mathrm{HCO} 3-$ of $17 \mathrm{mEq} / \mathrm{L}$, albumin of $0.9 \mathrm{~g}$ / $\mathrm{dL}$, and a serum calcium level below detectable range. Additionally, the ethanol level was $106 \mathrm{mg} / \mathrm{dL}$, PT of 26.1 seconds, INR of 2.46, and an aPTT of 96.3 seconds.

Electrocardiographic monitoring showed ventricular fibrillation and the first defibrillation attempt was unsuccessful at 9:04 AM with 200 Joules (J). He was given a total of $28 \mathrm{mg}$ of epinephrine (the first 11 doses administered as IV push followed by an infusion titrated to deliver approximately $1 \mathrm{mg}$ IV every 4 minutes); 12 more defibrillation attempts with escalating doses up to 360J (the last nine attempts were performed after core temperature improvement with rewarming measures); $100 \mathrm{mEq}$ of IV sodium bicarbonate; $2 \mathrm{gm}$ of IV magnesium; $100 \mathrm{mg}$ of IV lidocaine; $450 \mathrm{mg}$ of IV amiodarone; and $400 \mathrm{mg}$ of IV thiamine. Return of spontaneous circulation (ROSC) was achieved at 10:46 AM. The ventricular fibrillation spontaneously converted to a bradycardic rhythm at $36 \mathrm{bpm}$, with electrocardiogram (ECG) showing Osborn waves. The total duration of CPR was 108 minutes. At the time of ROSC, the patient's core temperature was $23.8^{\circ} \mathrm{C}\left(74.8^{\circ} \mathrm{F}\right)$. An overview of cardiac arrest interventions is illustrated in Figure 1.

\section{Hospital Course}

He required vasopressor support with epinephrine IV infusion at $8 \mathrm{mcg} / \mathrm{min}$. He was then admitted to the medical ICU to continue rewarming with external rewarming modalities (ie, Artic Sun ${ }^{\circledR}$ and Bair Hugger ${ }^{\mathrm{TM}}$ ). A temperature of $30.1^{\circ} \mathrm{C}\left(86.2^{\circ} \mathrm{F}\right)$ was finally achieved at $4: 00 \mathrm{pm}(7$ hours after cardiac arrest).

Streptococcus parasanguinis was present in two of the four blood culture bottles and appropriate antibiotics were initiated. He was extubated on day 5 post arrest with a GCS of 15 . The patient was discharged on day 15 post arrest, neurologically intact with no organ damage during his hospital stay.

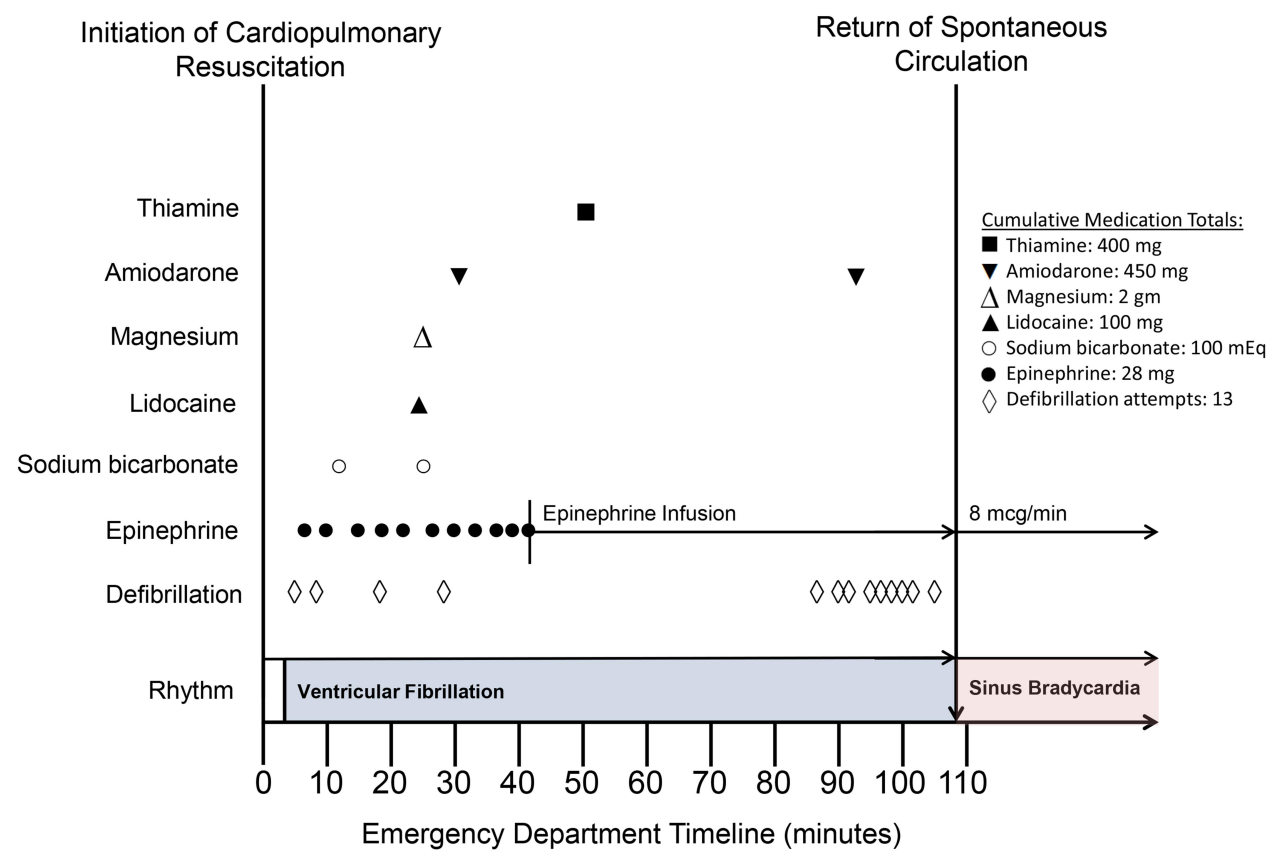

Figure I Overview of cardiac arrest interventions. Compressions and pulse checks were performed per advanced cardiac life support (ACLS). 


\section{Discussion}

Management of the accidental hypothermia patient is important even to healthcare facilities located in temperate climates. Our patient case occurred in Houston, Texas, a climate described as humid subtropical with tropical influences. ${ }^{1}$ Patient characteristics at risk of hypothermia include neonates, immobility, unconsciousness, intoxication, and very advanced age. Excessive ethanol consumption may significantly predispose persons to hypothermia due to its vasodilatory properties and immobility leading to prolonged exposure. ${ }^{2}$ Post-resuscitation evaluation revealed an ethanol level of $106 \mathrm{mg} / \mathrm{dL}$.

Hypothermia is typically classified into mild hypothermia $\left(>34^{\circ} \mathrm{C}\left[93.2^{\circ} \mathrm{F}\right]\right)$, moderate hypothermia $\left(30-34^{\circ} \mathrm{C}\right.$ [86-93.2 $\left.\left.{ }^{\circ} \mathrm{F}\right]\right)$, and severe hypothermia $\left(<30^{\circ} \mathrm{C}\left[86^{\circ} \mathrm{F}\right]\right){ }^{3}$ Our patient's condition was classified as severe hypothermia with a core temperature of $21^{\circ} \mathrm{C}\left(69.8^{\circ} \mathrm{F}\right)$. Key management principles of severe accidental hypothermia management involve the following tenets: initiating core rewarming, recognizing risk factors for rescue collapse, and providing cardiopulmonary support until completely rewarmed.

\section{Rewarming Principle and Techniques}

In accidental hypothermia, rewarming is a crucial cornerstone of treatment. When treating hypothermic patients, healthcare professionals should remember the mantra that "no one is dead until warm and dead". ${ }^{4}$ Unless a patient shows obvious signs of being dead (eg, decomposition, rigor mortis, and irreversible severe bodily injuries), healthcare professionals should continue lifesaving treatment until the patient is sufficiently warmed. ${ }^{3}$

Rewarming techniques have three different classifications: passive external, active external, and active internal (core) rewarming. All three techniques have a role in severe hypothermia management.

Prehospital warming usually includes passive external techniques: removing a patient's wet clothing to limit heat loss and full-body insulation as available with wool blankets and a warm environment. Active rewarming techniques are typically not used in prehospital settings as it may delay transport to a hospital. In addition, first-responders can ensure transport to a hospital with extracorporeal life support capabilities. ${ }^{4,5}$

Once the severely hypothermic patient arrives at the hospital, patients with a perfusing rhythm can be aggressively treated with active external and active internal warming techniques. Active external techniques include forced air devices to warm the patient's surface. Active internal (core) rewarming techniques may include warmwater lavage of the thoracic cavity, warmed IV or intraosseous (IO) fluids and warm humidified oxygen. In patients with severe hypothermia and cardiac arrest, active internal (core) rewarming with extracorporeal blood rewarming is often used for immediate central warming while providing beneficial circulatory support.

Extracorporeal blood rewarming has been used successfully in severely hypothermic patients with cardiac arrest with favorable neurological outcomes. ${ }^{6,7}$ Two observational studies in hypothermic patients showed 39.1-47\% survival with extracorporeal blood. ${ }^{6,7}$ However, extracorporeal blood rewarming may not be available at all medical centers. If available, extracorporeal blood rewarming with ECMO can also be time intensive to set up (possibly up to 6 hours) and labor intensive to continue. ${ }^{8}$

Transfer to an extracorporeal rewarming site is not always possible and capable hospitals may need additional time to set up their machines. Therefore, it is crucial to look at the outcomes of severely hypothermic patients without extracorporeal blood rewarming. Several case reports have detailed full neurological recovery in severely hypothermic patients with cardiac arrest who did not receive extracorporeal blood rewarming. ${ }^{9-13}$

\section{Rescue Collapse}

In the hypothermic patient, rough handling can precipitate post-rescue cardiac arrest (rescue collapse). In order to decrease position associated changes in venous return, ideally, patients should be transported horizontally to prevent rescue collapse. ${ }^{5}$ Furthermore, it is extremely important to handle the patient carefully during physical exam and essential procedures in order to decrease the risk of arrhythmias, including ventricular fibrillation. ${ }^{5}$

Once the hypothermic patient enters cardiac arrest, successful resuscitation can potentially take hours. ${ }^{9,14}$ Despite the long resuscitation time, severely hypothermic patients can recover neurologically intact. ${ }^{9}$ Thus, providers should focus on rewarming the patient and providing adequate cardiac support until the patient is completely rewarmed.

\section{Controversy}

There were differences in outcomes between patients with an unwitnessed cardiac arrest and those who did not have cardiac arrest at first rescuer arrival. In the 15 patients with an unwitnessed cardiac arrest, none of the 8 patients who 
received extracorporeal membrane oxygenation (ECMO) survived. On the other hand, in patients who later suffered cardiac arrest after first rescuer arrival, 9 of 15 patients who underwent ECMO survived (this includes 7 of 13 rescue collapse patients who survived after ECMO). This indicates accidental hypothermia patients with witnessed cardiac arrest may have better survival. ${ }^{7}$

\section{ACLS Technique - Defibrillation Current Guidelines}

Arrhythmias are common due to the low core temperatures in severe hypothermia. Sinus bradycardia may be initially present; however, conversion to atrial fibrillation then ventricular fibrillation and asystole may occur. ${ }^{4}$ There is controversy surrounding defibrillation attempts in hypothermia patients with ventricular tachycardia (VT) or ventricular fibrillation (VF) present. The European Resuscitation Council recommends defibrillation according to standard protocols; if ventricular fibrillation persists after three attempts, delay further defibrillation attempts until the core temperature is greater than $30^{\circ} \mathrm{C} .{ }^{4}$ The AHA guidelines recommend defibrillation when VT or VF is present and to consider further defibrillation attempts according to the Basic Life Support (BLS) algorithm with rewarming strategies. ${ }^{3}$ In contrast with the ERC, AHA guidelines state the value of delaying defibrillation attempts until a target temperature is uncertain. ${ }^{3}$ The AHA guideline recommendations are based on a low level of evidence. ${ }^{3}$ Overall, the temperature at which defibrillation should first be attempted and number of defibrillation attempts in severely hypothermic human patients have also not been firmly established.

\section{Controversy}

It is traditionally believed hypothermic hearts are unresponsive to defibrillation attempts. Human case series have revealed refractory ventricular arrhythmias, but successful defibrillation attempts and spontaneous conversions have also been described in core temperatures between $24^{\circ} \mathrm{C}$ and $29^{\circ} \mathrm{C} .{ }^{15}$ Hypothermia alters cardiac ion channel function which may impair defibrillation; however, animal models have demonstrated better success with defibrillation in hypothermic animals versus normothermic animals. ${ }^{16,17}$ In these animal studies, resuscitation efforts were initiated less than 10 minutes of induced ventricular fibrillation. Therefore, these animal studies closely mirror rescue collapse rather an unwitnessed cardiac arrest in hypothermia situations. Our patient arrested during transport from the ambulance to our ED with very short down time prior to CPR and received numerous unsuccessful defibrillations during resuscitation. Finally, our patient spontaneously converted 108 minutes after CPR initiation with a core temperature of $23.8^{\circ} \mathrm{C}\left(74.8^{\circ} \mathrm{F}\right)$.

\section{Medications}

Similar to defibrillation attempts, the use of vasopressors and other medications are also unclear. It has been proposed the metabolism of these medications may be impaired and could accumulate to toxic levels in hypothermic patients. ${ }^{4}$ Previously, guidelines recommended administering vasoactive medications only when a patient's temperature is $>30^{\circ} \mathrm{C}$.

In animal studies, vasoactive drug administration appear to be associated with increased rates of return of spontaneous circulation (ROSC). ${ }^{18}$

Guidelines have approached recommendations following these animal studies differently. Currently, AHA considers the administration of vasoactive medications to be reasonable according to the ACLS algorithm. On the other hand, ERC recommends withholding all drugs until a core temperature of $30^{\circ} \mathrm{C}$. In addition, ERC recommends the dosing interval of medications be doubled when the patient's temperature is $30-34.9^{\circ} \mathrm{C}$. For our patient, medications were administered according to the ACLS algorithm.

\section{Overview of Patient Treatment}

The first cornerstone of treating a patient suffering from hypothermia is rewarming. In our patient, we used a combination of passive external warming techniques (removing wet clothing), active external rewarming techniques (forced warm air), and active internal (core) rewarming techniques (warmed crystalloid irrigation of body cavities and administration via IV and IO routes). The ERC guidelines recommend contacting the hospital in advance and arranging transport to an extracorporeal blood rewarming-capable center. Extracorporeal blood rewarming is not commonly used for this purpose at our facility as accidental hypothermia cases are uncommon in our typically subtropical climate. Despite the lack of extracorporeal blood rewarming, our patient was successfully resuscitated using a combination of other rewarming techniques.

Another cornerstone of treatment in a patient with hypothermia is preventing rescue collapse. Our case patient went into ventricular fibrillation while transferring the patient from the ambulance bay to the hospital. The combination of the patient's altered mental status, 
agitation, and combativeness further increased the chance of rescue collapse. The risk of rescue collapse may have been decreased with more careful handling of the patient.

Once a patient enters cardiac arrest, the optimal treatment with defibrillation remains unclear. After our patient went into ventricular fibrillation (VF), we initiated standard AHA ACLS protocol with external/internal rewarming. There are concerns the hypothermic heart may be unresponsive to defibrillation. In our patient, defibrillation was attempted 13 times and all defibrillation attempts were unsuccessful. Fortunately, the patient's VF spontaneously converted to sinus bradycardia after 108 minutes of CPR with a core temperature of $23.8^{\circ} \mathrm{C}\left(74.8^{\circ} \mathrm{F}\right)$. Small studies have indicated good success with defibrillation in situations closely mirroring rescue collapse. The conversion to sinus rhythm despite a core temperature $<30^{\circ} \mathrm{C}$ may be because this patient suffered rescue collapse with short down time to CPR (ie, not an unwitnessed cardiac arrest). However, the many defibrillation attempts did not affect the patient's outcome.

In addition to unclear outcomes with defibrillation, there are concerns with vasoactive drug administration in hypothermic patients. In our patient, epinephrine (IV pushes and high-dose infusion approximating $1 \mathrm{mg}$ every 3-5 minutes) and antiarrhythmic medications (amiodarone and lidocaine) were administered. In total, our patient received $28 \mathrm{mg}$ of epinephrine during cardiac arrest. Furthermore, he was still hypothermic after ROSC and continued to require vasopressor support. Despite theoretical concerns of toxicity when administering vasoactive drugs during hypothermia, our patient suffered no such toxicity. Overall, our patient was discharged 15 days later neurologically intact with no organ damage.

\section{Implications for Practice, Education, and Research}

Institutions in warm climates, such as our facility, may not have much experience in treating accidental hypothermia cardiac arrest patients. Key points for personnel training include:

1. Rewarming the hypothermic patient is crucial; however, successful rewarming may take hours. While hypothermia patients may appear clinically dead, life-saving measures should be continued until the patient is successfully rewarmed unless injuries incompatible with life are present. Remember the mantra, "no one is dead until warm and dead".
2. If possible, first responders should discuss possible need for extracorporeal blood rewarming with institutions prior to hospital arrival. Emergency medical services responders may require training in treating and identifying the severely hypothermic patients, preventing rescue collapse, and transporting such patients to designated institutions offering extracorporeal blood rewarming capabilities, similar to transporting trauma patients to a designated trauma center.

3. Even if extracorporeal blood rewarming is unavailable, patients can recover completely intact with a combination of other rewarming techniques.

4. Preventing rescue collapse is an essential aspect of hypothermia treatment. All measures should be taken to avoid rough handling of the patient. Further studies are needed on sedating the severely hypothermic patients to prevent rescue collapse. It would be prudent to avoid agents with a risk of causing cardiac arrhythmias like antipsychotics.

5. Severe hypothermia patients with witnessed cardiac arrest, rescue collapse, or short down time prior to CPR may have a higher chance of full recovery.

6. The evidence concerning the use of vasoactive drugs and defibrillation during cardiac arrest in hypothermia is inconclusive and based on lowquality literature. This has led to different recommendations from AHA and ERC for administration of vasoactive drugs, number of shocks to be attempted, and ideal temperature for administering vasoactive drugs and defibrillation.

\section{Conclusion}

Successful resuscitation of severe accidental hypothermia with full recovery has been reported in the literature. In our case, the patient received non-ECMO rewarming techniques, numerous defibrillation attempts, and a large quantity of ACLS medications. He was discharged from our hospital 15 days later neurologically intact.

In patients with severe accidental hypothermia and cardiac arrest, patients should be completely rewarmed. Extracorporeal blood rewarming techniques are recommended, but not always readily available. Even if extracorporeal methods are unavailable, severely hypothermic patients can still have complete recovery. Evaluation of both AHA and ERC guidelines on accidental hypothermia are essential to all healthcare providers - even in subtropical climates. In addition, more literature is needed to clarify recommendations surrounding the use of vasoactive drugs, 
optimal temperature for defibrillation, and number of shocks to be attempted during treatment of cardiac arrest in severely hypothermic patients.

\section{Consent}

We have not had any success in locating the patient to obtain informed consent for publication of the case details; however, every effort has been made to sufficiently anonymize the details. Institutional review board approval was not required to publish the case details.

\section{Acknowledgments}

The open access publishing fees for this article have been partially covered by the Texas A\&M University Open Access to Knowledge Fund (OAKFund), supported by the University Libraries. This research did not receive any specific grant from funding agencies in the public, commercial, or not-for-profit sectors. Terence Chau and Merlyn Joseph are co-first authors for this study.

\section{Disclosure}

The authors report no conflicts of interest in this work.

\section{References}

1. Zhang K, Chen TH, Begley CE. Impact of the 2011 heat wave on mortality and emergency department visits in Houston, Texas. Environ Health. 2015;14:11. doi:10.1186/1476-069X-14-11

2. Kalant H, Le AD. Effects of ethanol on thermoregulation. Pharmacol Ther. 1983;23(3):313-364. doi:10.1016/0163-7258(83)90018-9

3. Vanden Hoek TL, Morrison LJ, Shuster M, et al. Part 12: cardiac arrest in special situations: 2010 American Heart Association Guidelines for cardiopulmonary resuscitation and emergency cardiovascular care. Circulation. 2010;122(18 Suppl 3):S829-861. doi:10.1161/ CIRCULATIONAHA.110.971069

4. Truhlar A, Deakin CD, Soar J, et al. European Resuscitation Council guidelines for resuscitation 2015: section 4. Cardiac arrest in special circumstances. Resuscitation. 2015;95:148-201. doi:10.1016/j. resuscitation.2015.07.017

5. Paal P, Gordon L, Strapazzon G, et al. Accidental hypothermia-an update: the content of this review is endorsed by the International Commission for Mountain Emergency Medicine (ICAR MEDCOM). Scand J Trauma Resusc Emerg Med. 2016;24(1):111.
6. Walpoth BH, Walpoth-Aslan BN, Mattle HP, et al. Outcome of survivors of accidental deep hypothermia and circulatory arrest treated with extracorporeal blood warming. $N$ Engl J Med. 1997;337 (21):1500-1505. doi:10.1056/NEJM199711203372103

7. Debaty G, Moustapha I, Bouzat P, et al. Outcome after severe accidental hypothermia in the French Alps: a 10-year review. Resuscitation. 2015;93:118-123. doi:10.1016/j.resuscitation.2015.06.013

8. Jarosz A, Kosinski S, Darocha T, et al. Problems and pitfalls of qualification for extracorporeal rewarming in severe accidental hypothermia. J Cardiothorac Vasc Anesth. 2016;30(6):1693-1697. doi:10.1053/j.jvca.2016.05.015

9. Kot P, Botella J. [Cardiac arrest due to accidental hypothermia and prolonged cardiopulmonary resuscitation]. Med Intensiva. 2010;34 (8):567-570. Spanish. doi:10.1016/j.medin.2009.12.001

10. Wolfe CS. Severe hypothermia associated with prolonged cardiorespiratory arrest and full recovery. J Am Board Fam Pract. 1993;6 (6):594-596.

11. Althaus U, Aeberhard P, Schupbach P, Nachbur BH, Muhlemann W. Management of profound accidental hypothermia with cardiorespiratory arrest. Ann Surg. 1982;195(4):492-495. doi:10.1097/00000658198204000-00018

12. Plaisier BR. Thoracic lavage in accidental hypothermia with cardiac arrest-report of a case and review of the literature. Resuscitation. 2005;66(1):99-104. doi:10.1016/j.resuscitation.2004.12.024

13. Gruber E, Beikircher W, Pizzinini R, et al. Non-extracorporeal rewarming at a rate of 6.8 degrees $\mathrm{C}$ per hour in a deeply hypothermic arrested patient. Resuscitation. 2014;85(8):e119-120. doi:10.1016/j.resuscitation.2014.05.011

14. Nordberg P, Ivert T, Dalen M, Forsberg S, Hedman A. Surviving two hours of ventricular fibrillation in accidental hypothermia. Prehosp Emerg Care. 2014;18(3):446-449. doi:10.3109/10903127.2014.891066

15. Clift J, Munro-Davies L. Best evidence topic report. Is defibrillation effective in accidental severe hypothermia in adults? Emerg Med J. 2007;24(1):50-51. doi:10.1136/emj.2006.044404

16. Ujhelyi MR, Sims JJ, Dubin SA, Vender J, Miller AW. Defibrillation energy requirements and electrical heterogeneity during total body hypothermia. Crit Care Med. 2001;29(5):1006-1011. doi:10.1097/ 00003246-200105000-00025

17. Boddicker KA, Zhang Y, Zimmerman MB, Davies LR, Kerber RE. Hypothermia improves defibrillation success and resuscitation outcomes from ventricular fibrillation. Circulation. 2005;111 (24):3195-3201. doi:10.1161/CIRCULATIONAHA.104.492108

18. Wira CR, Becker JU, Martin G, Donnino MW. Anti-arrhythmic and vasopressor medications for the treatment of ventricular fibrillation in severe hypothermia: a systematic review of the literature. Resuscitation. 2008;78(1):21-29. doi:10.1016/j.resuscitation.2008.01.025
Open Access Emergency Medicine

\section{Publish your work in this journal}

The Open Access Emergency Medicine is an international, peerreviewed, open access journal publishing original research, reports, editorials, reviews and commentaries on all aspects of emergency medicine. The manuscript management system is completely online and includes a very quick and fair peer-review system, which is all easy to use. Visit http://www.dovepress.com/testimonials.php to read real quotes from published authors. 